\title{
Curcumin protects against palmitic acid-induced apoptosis via the inhibition of endoplasmic reticulum stress in testicular Leydig cells
}

\author{
Zhi Chen ${ }^{1}$, Di Wen ${ }^{1}$, Fen Wang ${ }^{1}$, Chunbo Wang ${ }^{1}$ and Lei Yang ${ }^{2,3^{*}}$ (D)
}

\begin{abstract}
Background: Palmitic acid (PA) is a common saturated fatty acid that induces apoptosis in various types of cells, including testicular Leydig cells. There is evidence suggesting that PA is increased in patients with obesity and that PA-induced cell apoptosis may play an important role in obesity-related male infertility. Curcumin, a natural polyphenol, has been reported to exert cytoprotective effects in various cell types. However, the cytoprotective effect of curcumin against PA-induced apoptosis in Leydig cells remains unknown. Therefore, the current study was performed to investigate the protective effects of curcumin in response to PA-induced toxicity and apoptosis in murine Leydig tumor cell line 1 (MLTC-1) cells and explore the mechanism underlying its anti-apoptotic action.

Methods: MLTC-1 cells were cultured in Roswell Park Institute-1640 medium and divided into five groups. First four

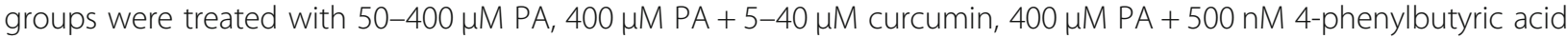
(4-PBA, an endoplasmic reticulum (ER) stress inhibitor), and $500 \mathrm{nM}$ thapsigargin (TG, an ER stress inducer) $+20 \mu \mathrm{M}$ curcumin, respectively, followed by incubation for $24 \mathrm{~h}$. Effects of PA and/or curcumin on viability, apoptosis, and ER stress in MLTC-1 cells were then determined by cell proliferation assay, flow cytometry, and western blot analysis. The fifth group of MLTC-1 cells was exposed to $400 \mu \mathrm{M}$ of PA and $5 \mathrm{IU} / \mathrm{mL}$ of human chorionic gonadotropin (hCG) for $24 \mathrm{~h}$ in the absence and presence of curcumin, followed by measurement of testosterone levels in cell-culture supernatants by enzyme-linked immunosorbent assay (ELISA). Rats fed a high-fat diet (HFD) were treated with or without curcumin for 4 weeks, and the testosterone levels were detected by ELISA.
\end{abstract}

Results: Exposure to 100-400 $\mu \mathrm{M}$ PA reduced cell viability, activated caspase 3, and enhanced the expression levels of the apoptosis-related protein BCL-2-associated $X$ protein (BAX) and ER stress markers glucose-regulated protein 78 (GRP78) and CCAAT/enhancer binding protein homologous protein (CHOP) in MLTC-1 cells. Treating cells with

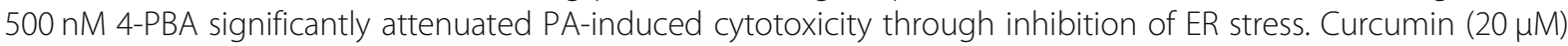
significantly suppressed PA- or TG-induced decrease in cell viability, caspase 3 activity, and the expression levels of BAX, CHOP, and GRP78. In addition, treating MLTC-1 cells with $20 \mu \mathrm{M}$ curcumin effectively restored testosterone levels, which were reduced in response to PA exposure. Similarly, curcumin treatment ameliorated the HFD-induced decrease in serum testosterone level in vivo.

(Continued on next page)

\footnotetext{
* Correspondence: yangleigeili@163.com

${ }^{2}$ Key Laboratory of System Bio-medicine of Jiangxi Province, Jiujiang

University, Jiujiang 332000, Jiangxi, China

${ }^{3}$ College of Basic Medical Science, Jiujiang University, Jiujiang 332000, Jiangxi,

China

Full list of author information is available at the end of the article
}

(c) The Author(s). 2019 Open Access This article is distributed under the terms of the Creative Commons Attribution 4.0 International License (http://creativecommons.org/licenses/by/4.0/), which permits unrestricted use, distribution, and reproduction in any medium, provided you give appropriate credit to the original author(s) and the source, provide a link to the Creative Commons license, and indicate if changes were made. The Creative Commons Public Domain Dedication waiver (http://creativecommons.org/publicdomain/zero/1.0/) applies to the data made available in this article, unless otherwise stated. 
(Continued from previous page)

Conclusions: The present study suggests that PA induces apoptosis via ER stress and curcumin ameliorates

PA-induced apoptosis by inhibiting ER stress in MLTC-1 cells. This study suggests the application of curcumin as a potential therapeutic agent for the treatment of obesity-related male infertility.

Keywords: Leydig cell, Palmitic acid, Apoptosis, Curcumin, Endoplasmic reticulum stress

\section{Background}

Obesity is known to be a major risk factor for male infertility, and therefore, obesity-associated male infertility is increasingly drawing public attention [1-4]. So far, the mechanisms underlying obesity-induced male infertility remain unclear. PA is the most common type of saturated free fatty acids (FFAs) in the plasma. It has been reported that FFAs, including PA, are increased in patients with obesity [5-7]. Elevation in the level of FFA, especially the saturated ones including PA, has been suggested to be closely associated with obesity-induced male infertility $[5,6,8]$. An earlier study has demonstrated that PA markedly suppresses cell survival and induces apoptosis in rat testicular Leydig cells in a time- and dose-dependent manner [9]. This suggests that Leydig cell toxicity induced by PA contributes to, or may even cause, reproductive abnormalities in obese men.

ER stress is defined as an imbalance between the protein load and the folding capacity of the ER, resulting in the accumulation of unfolded or misfolded proteins in the ER lumen. Therefore, the ER stress response is also commonly known as the unfolded protein response $[10,11]$. ER stress or impaired ER homeostasis has been reported to be closely associated with the pathology of reproductive diseases [12]. In a study on obese mice, ER stressmediated spermatocyte apoptosis was shown to be enhanced through CHOP and caspase-3 activation [13]. In addition, accumulating evidence suggests that ER stress is activated in various tissues under conditions related to obesity [10]. Excessive ER stress has been shown to ultimately induce cellular apoptosis [14]. Although PA has been implicated to induce apoptosis in rat testicular Leydig cells, the involvement of ER stress in this process remains unknown [9].

Curcumin is a phytochemical component isolated from turmeric (Curcuma longa L., Zingiberaceae), and because of its anti-oxidant, anti-inflammatory, and antiobesity activities, it has been widely used in studies on infertility and metabolic disorders, including obesity [15-19]. Curcumin has been reported to effectively attenuate ER stress-induced cell apoptosis in various cell types [20-22]. Nevertheless, it is still unclear whether curcumin exhibits protective effects through inhibition of ER stress against PA-induced injury in Leydig cells.

The aim of this study was to evaluate the effects of curcumin on PA-induced injury in MLTC-1 cells and further explore the mechanism by which curcumin ameliorates cell apoptosis. Besides, we determined the impact of curcumin on testosterone levels in PAexposed Leydig cells. Gaining a better understanding regarding the protective effects of curcumin and its mechanism of action against PA-induced injury in Leydig cells may be instrumental for the design of novel therapies for treating obesity-induced male infertility.

\section{Materials and methods Materials}

Curcumin, TG, 4-PBA, ethylene diamine tetra acetic acid (EDTA) and dimethyl sulfoxide (DMSO) were procured from Sigma-Aldrich (St Louis, Missouri, USA). The murine Leydig tumor cell line MLTC-1 was obtained from Cell Institute of Shanghai, Chinese Academy of Sciences (Shanghai, China). Radioimmunoprecipitation assay (RIPA) lysis buffer, phenylmethylsulfonyl fluoride (PMSF), trypsin and Tris-buffered saline-Tween-20 (TBST) were purchased from Solarbio (Beijing, China). RPMI 1640 medium was purchased from Hyclone (Utah, USA). Fetal bovine serum (FBS) was procured from Gibco (Grand Island, New York, USA). Caspase 3 Activity Colorimetric Assay Kit, Total Protein Extraction Kit, and bicinchoninic acid (BCA) Protein Assay Kit were purchased from the Nanjing Jiancheng Bioengineering Institute (Nanjing, China). Cell Counting Kit 8 (CCK 8) and Annexin V-fluorescein isothiocyanate (FITC)/Propidium Iodide (PI) Apoptosis Analysis Kit were obtained from Beijing Zoman Biotechnology Co., Ltd. (Beijing, China). Testosterone ELISA Kit was purchased from Ji Yin Mei (Wuhan, China). Rabbit anti-mouse primary antibodies against BAX (sc-4239) and $\beta$-actin (sc-517,582) were obtained from Santa Cruz Biotechnology, Inc. (Santa Cruz, California, USA). Rabbit anti-mouse primary antibodies against CHOP (ab10444) and GRP78 (ab32618) were purchased from Abcam (Cambridge, UK). The goat anti-rabbit secondary antibodies were procured from Proteintech (Wuhan, China).

\section{Cell culture and treatment}

In brief, MLTC-1 cells were cultured in RPMI 1640 medium supplemented with 10\% FBS, penicillin (100 $\mathrm{IU} / \mathrm{mL})$, and streptomycin $(100 \mu \mathrm{g} / \mathrm{mL})$ and maintained at $37^{\circ} \mathrm{C}$ in a humidified incubator containing 95\% air and 5\% $\mathrm{CO}_{2}$. Curcumin, 4-PBA, and TG were 
prepared in DMSO with a final DMSO concentration of no more than $0.1 \%(\mathrm{v} / \mathrm{v})$. After reaching $70-80 \%$ confluency, cells were divided into four groups, treated with various concentrations of PA $(0,50,100$, 200, and $400 \mu \mathrm{M})$, PA $(400 \mu \mathrm{M})+$ curcumin $(0,5,10$, 20 , and $40 \mu \mathrm{M})$, PA $(400 \mu \mathrm{M})+4-\mathrm{PBA}(500 \mathrm{nM})$, and TG $(500 \mathrm{nM})+$ curcumin $(20 \mu \mathrm{M})$, respectively, followed by incubation for $24 \mathrm{~h}$ (Fig. 1). Cells were then collected to detect viability, apoptosis, and caspase 3 activity, and used to perform western blot analysis (Fig. 1).

\section{Estimation of cell viability}

To explore the toxic effects of PA on Leydig cells, MLTC-1 cells were treated with increasing concentrations of PA $(0-400 \mu \mathrm{M})$, and cell viability was determined by CCK- 8 assay according to the manufacturer's instructions. Briefly, MLTC-1 cells were seeded at a density of $2 \times 10^{4}$ cells per well in 96-well plates. After the incubation of cells with different treatments for $24 \mathrm{~h}$, $10 \mu \mathrm{L}$ of CCK-8 solution was added to each well. Cells were then incubated for $2 \mathrm{~h}$ at $37^{\circ} \mathrm{C}$, followed by measurement of absorbance at $405 \mathrm{~nm}$ using a microplate reader (Bio-Rad 680, CA, USA). All experiments were performed in triplicate.

\section{Cell apoptosis assay}

After various treatments, MLTC-1 cells were washed with PBS, digested with $0.25 \%$ EDTA-free trypsin and harvested. Thereafter, cells were centrifuged at $500 \times \mathrm{g}$ for $5 \mathrm{~min}$, washed twice with cold PBS, and adjusted to a final concentration of $1 \times 10^{5}$ cells $/ \mathrm{mL}$. Cells were initially re-suspended in $50 \mu \mathrm{L}$ of binding buffer, after which $5 \mu \mathrm{L}$ of PI was added, and the mixture was then incubated for $15 \mathrm{~min}$ at room temperature in the dark. Finally, $450 \mu \mathrm{L}$ of binding buffer and $1 \mu \mathrm{L}$ of Annexin VFITC were added, and samples were further incubated for $15 \mathrm{~min}$ in the dark. Apoptosis was detected by flow cytometry (FACSCalibur ${ }^{\mathrm{rm}}$, BD Biosciences, CA, USA) within $1 \mathrm{~h}$ of the last incubation. Measurements for each sample were conducted in triplicate.

\section{Western blot analysis}

After different treatments, cells were harvested and total protein was extracted using RIPA lysis buffer. Protein concentrations were then determined by BCA Protein Assay Kit. Each protein sample $(30 \mu \mathrm{g})$ was separated on $12 \%$ sodium dodecyl sulfate (SDS)-polyacrylamide gels and then electrotransferred onto polyvinylidene fluoride (PVDF) membranes. Membranes were then blocked with $10 \%$ nonfat milk in TBST for $2 \mathrm{~h}$ and incubated overnight with anti- $\beta$-actin, anti-BAX, anti-CHOP, and antiGRP78 primary antibodies at $4{ }^{\circ} \mathrm{C}$. Thereafter, these blots were incubated with horseradish peroxidaseconjugated secondary antibodies (1:4000) for $30 \mathrm{~min}$ at $37^{\circ} \mathrm{C}$. The immunoreactive bands on membranes were visualized using SuperSignal West Pico Kit (Proteintech, Wuhan, China) and detected by Bio-Rad imaging system (Bio-Rad, CA, USA), according to the manufacturer's instructions. Densitometric analysis was performed using ImageJ software 1.48 (Bethesda, MD, USA).

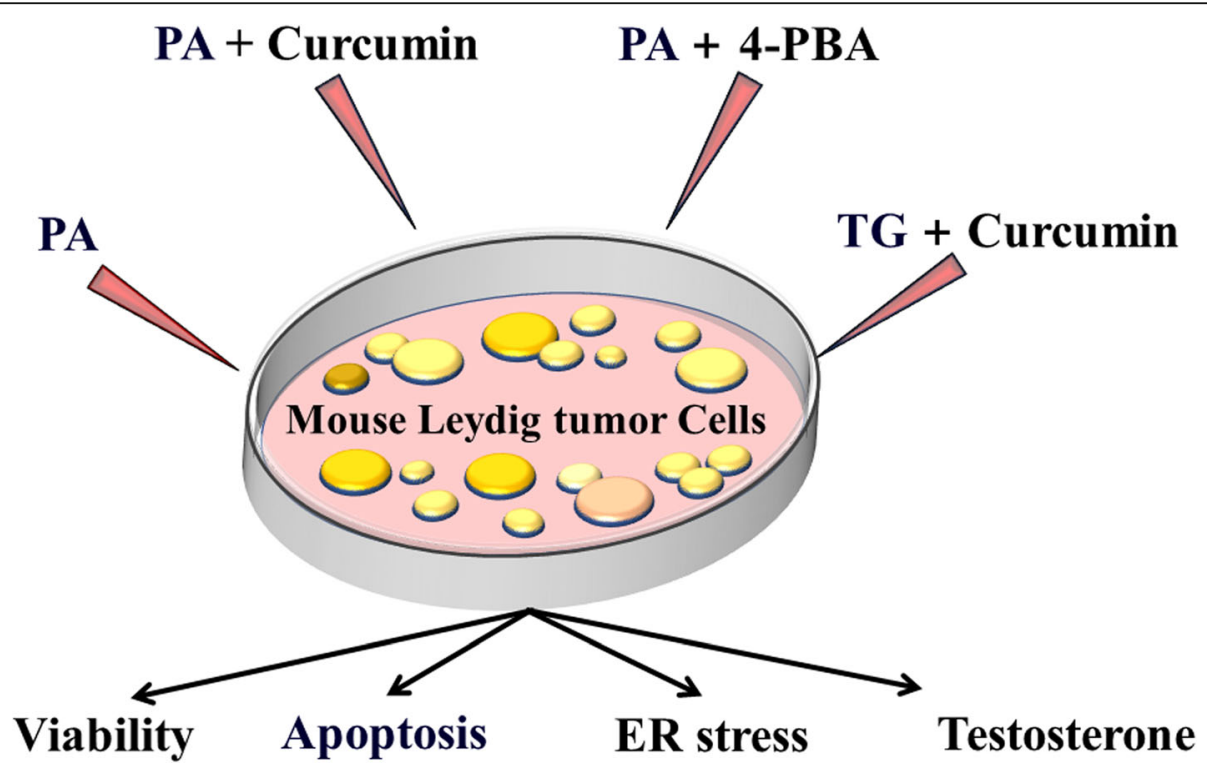

Fig. 1 Schematic of the experimental design. MLTC-1 cells were treated with PA, PA + curcumin, PA + 4-PBA or TG + curcumin to explore the mechanism of curcumin that protects against PA induced cell apoptosis 


\section{Caspase 3 activity measurement}

Caspase 3 activity was measured using Caspase-3 Activity Colorimetric Assay Kit according to the manufacturer's instructions. After different treatments, MLTC-1 cells were harvested by centrifugation and incubated in lysis buffer on ice for $15 \mathrm{~min}$. Cell lysates were then centrifuged at $15,000 \mathrm{rpm}$ for $15 \mathrm{~min}$ at $4{ }^{\circ} \mathrm{C}$. The protein content was determined using the BCA Protein Assay Kit. Sample aliquots were then incubated with the caspase 3 substrate in a microplate at $37^{\circ} \mathrm{C}$ for $4 \mathrm{~h}$ and the absorbance was recorded at $405 \mathrm{~nm}$ using a microplate reader (Bio-Rad 680, CA, USA).

\section{Animal care and treatment}

All the animal experiments performed in the present study were approved by the Committee for the Ethics on Animal Care and Experiments of Jiujiang University (approval No. SYXK(GAN)2019-0001). Male SpragueDawley rats $(n=40$, body weight: $220-240 \mathrm{~g})$ were obtained from the Experimental Animal Center of Jiujiang University. All rats were housed under conditions of controlled temperature $\left(20-25^{\circ} \mathrm{C}\right)$, humidity $(50 \pm 5 \%)$, and lighting ( $12 \mathrm{~h}$ light $/ 12 \mathrm{~h}$ dark cycle) with free access to food and water. Curcumin was dissolved by olive oil and administered orally by oral gavage. The rats were randomly divided into four groups, including a control group $(n=10)$, HFD group $(n=10)$, HFD + curcumin group $(n=10)$ and a curcumin group $(n=10)$. All rats were fed ad libitum with an HFD for 4 weeks, with the exception of those in the curcumin and control groups. The rats in the curcumin group and HFD + curcumin group were orally administered curcumin $(100 \mathrm{mg} / \mathrm{kg} /$ day $)$ for 4 weeks, while those in the control and HFD groups were administered an identical volume of the vehicle. Following treatment, the rats were anaesthetized with an intraperitoneal injection of sodium pentobarbital $(45 \mathrm{mg} / \mathrm{kg})$, and blood samples were obtained from the abdominal aorta.

\section{Testosterone measurement}

To evaluate the effects of curcumin on testosterone production in PA-treated MLTC-1 cells, cells were exposed to PA and/or curcumin, and testosterone levels were then determined in the culture medium using specific ELISA kits. In brief, the MLTC-1 cells were treated with PA $(400 \mu \mathrm{M})$ and/or curcumin $(20 \mu \mathrm{M})$, and co-incubated with $5 \mathrm{IU} / \mathrm{mL}$ hCG for $24 \mathrm{~h}$, followed by measurement of testosterone concentration in cellculture supernatants $(100,000 \mathrm{cell} / \mathrm{mL}$ culture supernatant) by employing a testosterone ELISA kit according to the manufacturer's instructions. Blood samples were obtained from the abdominal aorta. After centrifuging the samples at $1500 \mathrm{~g}$ and $4{ }^{\circ} \mathrm{C}$ for $10 \mathrm{~min}$, the supernatant sera were obtained for further detection. Serum level of testosterone was measured using kits, according to the manufacturer's instructions. The minimum detectable concentration of testosterone was $0.02 \mathrm{ng} /$ $\mathrm{mL}$. The intra- and inter-assay coefficients of variation were $<9$ and $<15 \%$, respectively. Assessment for each sample was carried out in triplicate.

\section{Statistical analysis}

The data were analyzed by ANOVA, followed by Fisher's least significant difference test and independent samples Student's t test, with SPSS software, version 13.0 (SPSS, Chicago, IL, USA). All the data are presented as a mean \pm standard error of the mean (SEM). For all analysis, $p$ values of $<0.05$ were considered statistically significant.

\section{Results}

PA induces apoptosis via the activation of ER stress in MLTC-1 cells

As indicated in Fig. 2a, PA $(100-400 \mu \mathrm{M})$ significantly decreased cell viability. To investigate whether the decreased cell viability was due to the induction of apoptosis, PA-treated MLTC-1 cells were analyzed by flow cytometry and western blotting. The results demonstrated that treatment of cells with 100$400 \mu \mathrm{M}$ PA increased the expression of apoptosisrelated genes caspase 3 and BAX in a dose-dependent manner (Fig. 2b-d). After treating cells for $24 \mathrm{~h}$ with 50-400 $\mu \mathrm{M}$ PA, we determined the expression of ER stress marker genes (GRP78 and CHOP) by western blot analysis. The results demonstrated a dosedependent increase in the expression of GRP78 and CHOP upon exposure to 100-400 $\mu \mathrm{M}$ PA (Fig. 2c, e, f). At $400 \mu \mathrm{M}$, the cell viability decreased to approximately $40 \%$, and apoptosis-related genes and ER stress marker genes showed elevated expression. We therefore used $400 \mu \mathrm{M}$ in the subsequent PA treatments.

\section{Curcumin attenuates PA-induced cytotoxicity and ER stress in MLTC- 1 cells}

To determine the effect of curcumin on Leydig cell viability, MLTC-1 cells were treated with different curcumin concentrations $(5-40 \mu \mathrm{M})$ for $24 \mathrm{~h}$. As shown in Fig. 3a, curcumin concentrations up to $20 \mu \mathrm{M}$ did not alter the viability of MLTC-1 cells, whereas $40 \mu \mathrm{M}$ curcumin significantly decreased cell viability compared to that of the control group cells. Furthermore, reduced cell viability due to treatment with $400 \mu \mathrm{M}$ PA was observed to be restored in response to $20 \mu \mathrm{M}$ curcumin (Fig. 3b). Meanwhile, $20 \mu \mathrm{M}$ curcumin was shown to effectively reduce caspase 3 activity and the expression of BAX protein (Fig. 3c-e). In addition, $400 \mu \mathrm{M}$ PA-induced increase in GRP78 and CHOP expression was inhibited by $20 \mu \mathrm{M}$ curcumin (Fig. 3e-g). Interestingly, we observed that the $40 \mu \mathrm{M}$ curcumin group had lower 


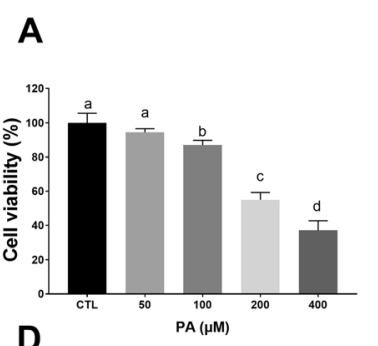

B

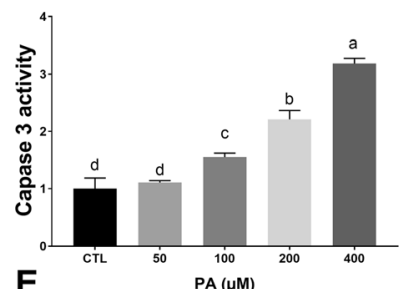

E
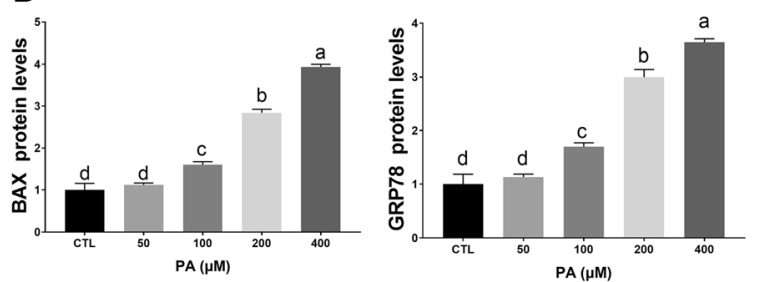

C
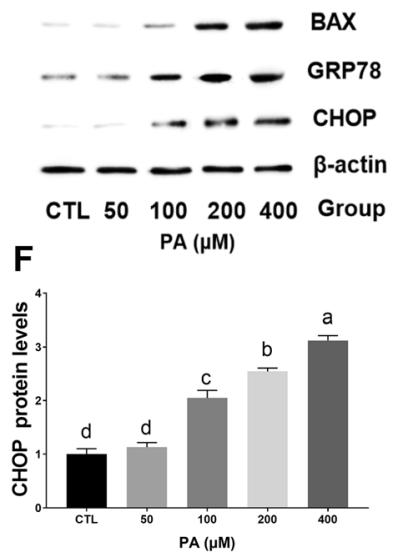

Fig. 2 PA induces apoptosis and ER stress in MLTC-1 cells. Cells were treated with increasing concentrations of PA (50-400 $\mu \mathrm{M}$ ) for $24 \mathrm{~h}$, and cell viability was measured by CCK 8 assay (a). Caspase-3 activity was measured using the Caspase-3 Activity Colorimetric Assay (b). Western blot analysis (c) was performed to detect the relative expression of apoptosis-related BAX (d) and ER stress marker GRP78 (e) and CHOP (f). The proteins expression levels were normalized to $\beta$-actin. The statistical analysis results are shown in the bar graphs. The data are represented as the mean \pm SEM of three independent experiments. Bars with different letters are significantly different $(p<0.05)$

cell viability than the $20 \mu \mathrm{M}$ group and higher viability than the PA-treated group (Fig. 3b). Similarly, the $40 \mu \mathrm{M}$ curcumin group had higher caspase 3 activity and expression of BAX and GRP78 than the $20 \mu \mathrm{M}$ group (Fig. 3c-f). However, no significant difference was observed in the CHOP expression between the $20 \mu \mathrm{M}$ group and $40 \mu \mathrm{M}$ group (Fig. 3e, g).

4-PBA attenuates PA-induced cytotoxicity, apoptosis, and ER stress in MLTC-1 cells

The CCK 8 assay and flow cytometric analysis revealed that PA-exposure significantly reduced cell viability and induced apoptosis, while treatment with 4-PBA effectively restored cell viability and inhibited apoptosis (Fig. 4a-c). In addition, it was observed that 4-PBA treatment markedly reduced caspase 3 activity and the expression of BAX, GRP78, and CHOP in the PAtreated MLTC-1 cells (Fig. 4d-h).

\section{Curcumin protects MLTC- 1 cells against TG-induced cytotoxicity, ER stress, and apoptosis in MLTC- 1 cells} As expected, TG induced reduction in MLTC-1 cell viability, increased ER stress markers GRP78 and CHOP, and activated caspase 3 and BAX, while treating cells

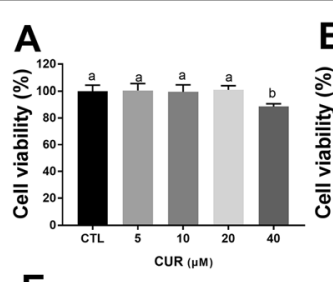

E

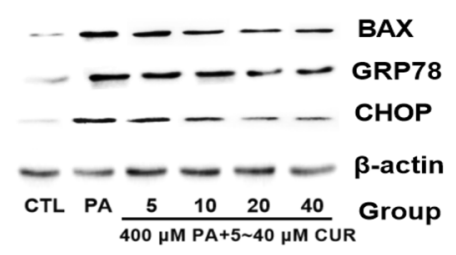

C

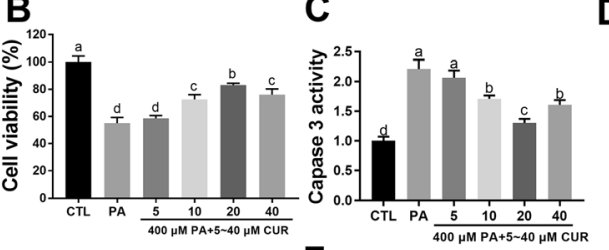

$\mathbf{F}$

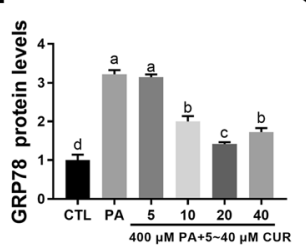

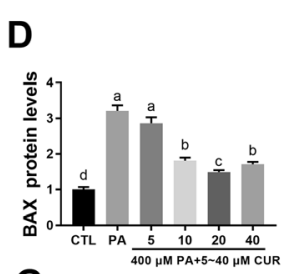

G

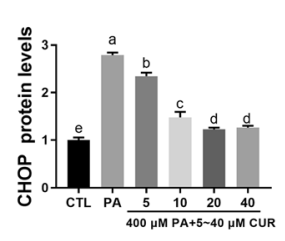

Fig. 3 Curcumin attenuates the PA-induced apoptosis and ER stress in MLTC-1 cells. Cells were treated with different concentrations of curcumin $(5-40 \mu \mathrm{M})$ in the absence $(\mathbf{a})$ and presence $(\mathbf{b})$ of PA $(400 \mu \mathrm{M})$ for $24 \mathrm{~h}$ and then processed for cell activity analysis CCK 8 assay. Caspase-3 activity was measured using the Caspase-3 Activity Colorimetric Assay (c). Western blot analysis (e) was performed to detect the relative expression of apoptosis-related BAX (d) and ER stress marker GRP78 (f) and CHOP (g). The proteins expression levels were normalized to $\beta$-actin. The statistical analysis results are shown in the bar graphs. The data are represented as the mean \pm SEM of three independent experiments. Bars with different letters are significantly different $(p<0.05)$ 


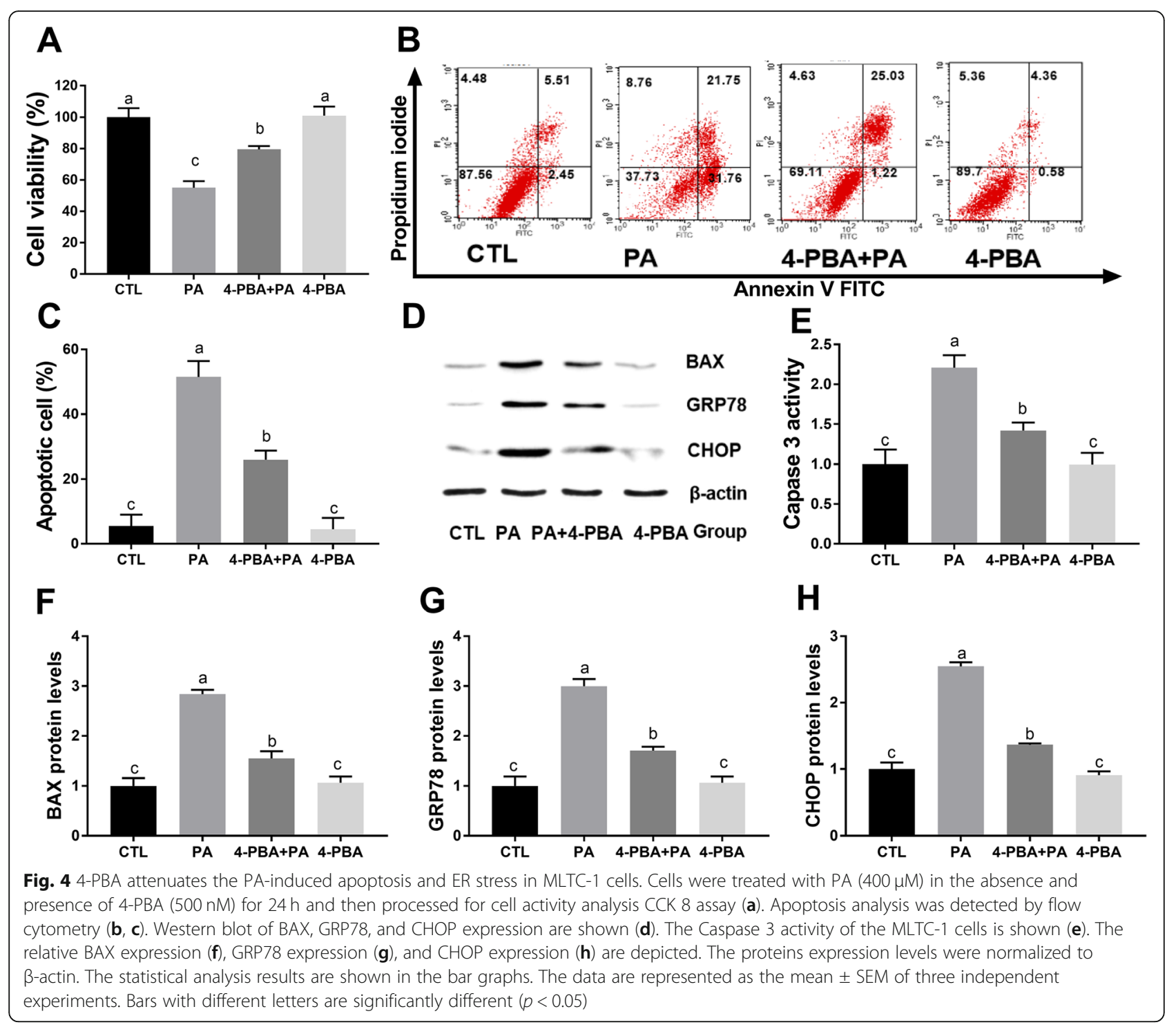

with $20 \mu \mathrm{M}$ curcumin significantly restored viability and inhibited TG-induced ER stress and apoptosis (Fig. 5).

\section{Curcumin restores PA-mediated inhibition of testosterone secretion in MLTC- 1 cells}

Testosterone secretion was stimulated in MLTC-1 cells by the addition of hCG to PA-containing culture medium in which cells were incubated for $24 \mathrm{~h}$. As shown in Fig. 6a, in $400 \mu \mathrm{M}$ PA-treated cells, concentration of testosterone was significantly decreased compared to that in untreated control cells, whereas curcumin significantly attenuated the reduction of testosterone secretion in MLTC-1 cells exposed to PA. Subsequently, we explored the effect of curcumin on testosterone production in HFD-fed rats. We found that rats fed an HFD exhibited abnormal serum hormone levels, manifested as reduced serum levels of testosterone.
Serum testosterone levels were observed to be restored following treatment with curcumin (Fig. 6b).

\section{Discussion}

Curcumin, a natural diphenolic compound, possesses numerous health beneficial effects such as antiinflammatory, anti-obesity, and antioxidant properties [15-19]. Due to its pharmacological efficacy, curcumin has been studied widely in various research areas. In this work, we demonstrated that PA reduced Leydig cell viability, activated caspase 3 , and enhanced the expression levels of apoptosis-related protein BAX and ER stress markers GRP78 and CHOP. Curcumin significantly suppressed PA-induced decrease in cell viability and the expression levels of apoptosis-related protein and ER stress markers. In addition, curcumin could restore PA- 

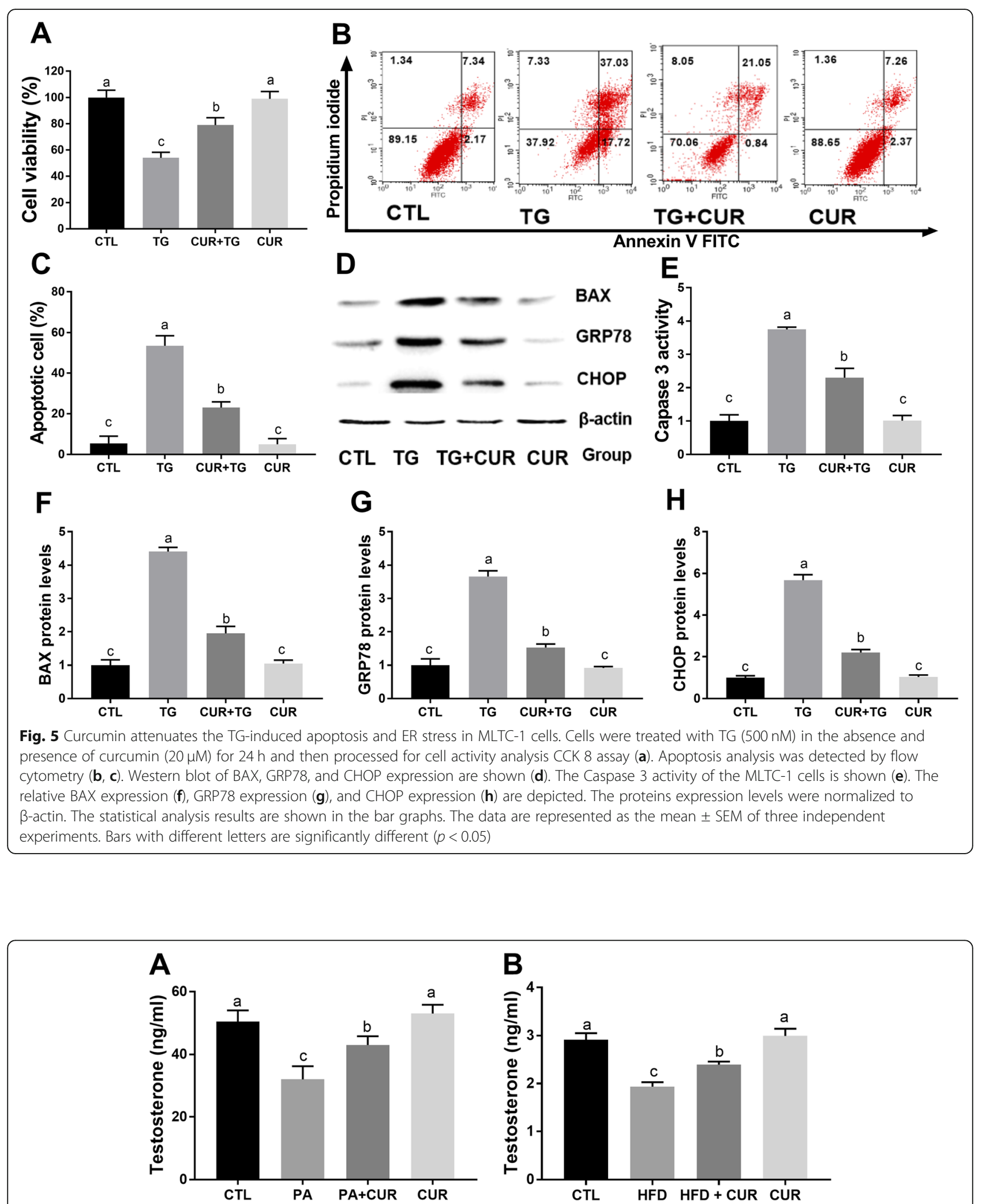

Fig. 6 Effects of curcumin on testosterone generation in PA-treated MLTC-1 cells. MLTC-1 cells were treated with hCG for $24 \mathrm{~h}$ and the concentration of testosterone in the culture supernatants was then measured employing the ELISA assay (a). The rats were orally administered curcumin for 4 weeks, and serum level of testosterone was measured using the ELISA assay (b). The statistical analysis results are shown in the bar graphs. Data are presented as the mean \pm SEM of three independent experiments. Bars with different letters are significantly different $(p<0.05)$ 
or HFD-mediated inhibition of testosterone secretion by Leydig cells in vitro and in vivo.

The increase in the male infertility rates has been reported to be in parallel with the increasing rates of obesity [23]. Studies have shown that increased weight in men is correlated with lower testosterone levels and reduced fertility. Moreover, the odds of infertility have been reported to increase by approximately $10 \%$ for every $9 \mathrm{~kg}$ (20 pounds) a man is overweight [23, 24]. In addition to reduced plasma testosterone levels, obesity has also been associated with chronic elevation of plasma FFAs [9]. PA is a common type of saturated FFA and is known to increase in obese individuals. Recently, PA has been reported to cause toxicity in various types of cells, including Leydig cells. PA-mediated cytotoxicity was observed to occur via reduction of cell viability and induction of apoptosis [9, 25-28]. However, the molecular mechanism underlying PA-induced apoptosis in Leydig cells is still not well understood. To investigate the possible PA-induced apoptotic mechanisms in Leydig cells, we first determined the cytotoxicity of PA in MLTC-1 cells. In the present study, PA was found to activate caspase 3 and upregulate BAX protein expression in a dose-dependent manner in order to induce apoptosis in MLTC-1 cells, which is in agreement with a previous study [9]. Earlier reports have suggested that PA induces apoptosis in different types of cells by activating ER stress-mediated apoptotic pathways [27, 29, 30]. To confirm the role of ER stress in PA-induced MLTC-1 cell apoptosis, we checked the expression of ER stress marker genes GRP78 and CHOP. Our data showed a significant dose-dependent increase in the expression of GRP78 and CHOP proteins in PA-treated MLTC-1 cells. These results indicate that inhibition of ER stress in Leydig cells might effectively ameliorate the toxic effects of PA.

Curcumin is a phenolic compound that has been shown to play a significant protective role in inhibition of ER stress-mediated apoptosis [20, 31, 32]. In the current study, MLTC-1 cells were used as a suitable model to investigate the effects of curcumin on PAinduced cell injury and its underlying protective mechanism. Initially, the effects of curcumin on the viability and apoptosis of MLTC-1 cells were examined. Our data indicated that low concentrations of curcumin $(5-20 \mu \mathrm{M})$ ameliorated the PA-induced decrease in cell viability and reduced the expression of apoptosis-associated genes, including BAX and caspase 3, which is consistent with a previous study [22]. Based on these results, it was concluded that curcumin inhibits PA-induced apoptosis in Leydig cells. Interestingly, in this study, curcumin at $40 \mu \mathrm{M}$ was observed to show a negative impact on cell viability, indicating that curcumin may have cytotoxic effect at certain high concentrations. Although the reason for this cytotoxic effect has never been fully elucidated, we suspect that an exposure time of $24 \mathrm{~h}$ may be long enough for $40 \mu \mathrm{M}$ curcumin to accumulate in MLTC1 cells to cause apparent cell damage.

In this study, we have used $400 \mu \mathrm{M}$ PA and $20 \mu \mathrm{M}$ curcumin, which seem to be higher than that in vivo, to perform in vitro experiments. In fact, PA and curcumin can achieve 20 and $400 \mu \mathrm{M}$ in vivo by oral supplementation, respectively. Although curcumin's low oral bioavailability limited its application, many efforts have been carried out to improve its solubility and oral bioavailability in the past years. Nowadays, it has been transformed into a variety of different formulations, peak plasma concentration of curcumin in vivo is about $50-20,000 \mathrm{ng} /$ $\mathrm{mL}$ depending on the formulation [33-39]. The physiological concentration of PA in vivo is about $100 \mu \mathrm{mol} / \mathrm{L}$. Interestingly, in obese patients, plasmatic PA concentration rises up to three- to fivefold when compared with matched healthy subjects [40-42].

Curcumin was reported to inhibit ER stress caused by cerebral ischemia-reperfusion injury in rats [32]. Increased apoptosis was observed in the hearts of diabetic mice, which was attenuated by curcumin, ultimately improving cardiac function [43]. In the current study, our data revealed that the PA-induced increase in GRP78 and $\mathrm{CHOP}$ protein expression was suppressed by curcumin. These data indicate that curcumin might attenuate PA-induced cytotoxicity and ER stress in MLTC-1 cells. Additionally, to check the involvement of ER stress in apoptosis induced by PA, 4-PBA was used as an ER stress inhibitor, and as expected, it was observed that inhibition of ER stress by 4-PBA attenuated the PAinduced cell apoptosis. However, curcumin was shown to protect MLTC-1 cells against reduction of viability, apoptosis and ER stress caused by the ER stress inducer TG. These results further confirmed that ER stress was indeed involved in PA-induced MLTC-1 cell apoptosis and that curcumin can indeed protect Leydig cells against TG- or PA-induced damage through inhibition of ER stress response.

Realizing the importance of Leydig cells in testosterone secretion, we subsequently explored the effects of PA and/or curcumin on testosterone secretion in MLTC-1 cells. As expected, PA treatment significantly decreased the production of testosterone in MLTC-1 cells, while curcumin restored testosterone levels effectively. We then investigated the effects of curcumin on testosterone production in diet-induced obesity male rats. Rats fed an HFD were treated with or without curcumin for 4 weeks. We found that the testosterone levels were decreased in rats fed an HFD, and treatment with curcumin upregulated the decreased levels of serum testosterone. The results of the present study suggested that curcumin treatment may ameliorate diet-induced 
reduction of testosterone levels. Similar to this, an earlier study showed that curcumin ameliorated HFD-induced decrease in serum testosterone and reduced HFDinduced spermatogenesis dysfunction and apoptosis [16]. These findings suggest that PA may play an important role in male infertility and that curcumin can be used as a promising therapeutic agent for treating obesityassociated male infertility.

A critical factor considered to affect serum and/or intratesticular testosterone levels is the number of Leydig cells. Physiologically, in a normal testis, a certain degree of apoptosis can be observed, which plays an important role in discarding decrepit and abnormal cells, thereby maintaining the population of Leydig cells and testosterone levels [44]. Excessive Leydig cell apoptosis caused by testis impairment could result in decreased testosterone levels, leading to apoptosis of spermatogenic cells, causing infertility. Interestingly, in a study by $\mathrm{Mu}$ et al., excessive activation of autophagy was observed in sperm samples from obese male patients, and inhibition of autophagy was observed to improve the decreased fertility of obese male mice [8]. Therefore, in the present study, PA was shown to decrease the number of MLTC-1 cells and compromise the normal endocrine function of these cells, thereby suppressing the secretion of testosterone. Although curcumin restored testosterone production in PA-treated MLTC-1 cells, the precise mechanism through which it regulates the synthesis of testosterone in Leydig cells remains unclear and needs further investigation.

\section{Conclusions}

In summary, our results suggest that PA induces apoptosis in testicular Leydig cells through the ER stress signaling pathway. Furthermore, curcumin could potentially protect these cells from PA-induced apoptosis and restored testosterone production. These findings reflect the potential of natural compounds in the development of future therapeutic approaches for the treatment of obesity-related male infertility.

\footnotetext{
Abbreviations

4-PBA: 4-phenylbutyric acid; BAX: B-cell lymphoma-2 (BCL-2) associated X protein; BCA: Bicinchoninic acid; CHOP: CCAAT/enhancer binding protein homologous protein; CUR: Curcumin; DMSO: Dimethyl sulfoxide; EDTA: Ethylene diamine tetra acetic acid; ELISA: Enzyme-linked immunosorbent assay; ER: Endoplasmic reticulum; FBS: Fetal bovine serum; FFAs: Free fatty acids; FITC: Fluorescein isothiocyanate; GRP78: Glucoseregulated protein 78; hCG: Human chorionic gonadotropin; HFD: High-fat diet; LH: Luteinizing hormone; MLTC-1: Murine Leydig tumor cell line 1; PA: Palmitic acid; PI: Propidium iodide; PMSF: Phenylmethylsulfonyl fluoride; RIPA: Radioimmunoprecipitation assay; RPMI 1640: Roswell Park Institute1640; SDS: Sodium dodecyl sulfate; TBST: Tris-buffered saline-Tween-20; TG: Thapsigargin
}

\section{Acknowledgements}

We thank Lanjie Lei from Jiujiang University for all assays and analysis and interpretation of data.

\section{Authors' contributions}

ZC and LY designed the study and prepared the manuscript. ZC performed the experiments. DW, FW and CW assisted in the data analysis and helped prepare the manuscript. All authors read and approved the final manuscript.

\section{Funding}

This study was supported by the Natural Science Research Project of Education Department of Guizhou Province of China (QJH-KY-Z[2018]419, QJH-KY-Z[2018]420, QJ-[2015]337, QJH-KY-Z[2016]318), the Scientific Research Project of Qiannan Normal University for Nationalities (qnsyrc201610, QNSY2018BS018, qnsyzw1805), Qiannan Agricultural Science and Technology Program of Qiannan Science and Technology Bureau (QNKHNZ[2017]21, QNKHNZ[2018]01), the National Science Foundation of China 31560609, the Research and Innovation Team Foundation of Guizhou Province Education Department (201568), the Project of Science and Technology of Guizhou ([2014]7419, [2015]2134, QKH-J-20152136), Key Support Project for Biology in Qiannan Normal University for Nationalities and the National Natural Science Foundation of China(31660056).

\section{Availability of data and materials}

The datasets used and/or analyzed during the current study available from the corresponding author on reasonable request.

\section{Ethics approval and consent to participate}

All procedures were approved by the Committee for the Ethics on Animal Care and Experiments of Jiujiang University (approval No. SYXK(GAN)2019-0001).

\section{Consent for publication}

All authors agree to the submission of this article for publication.

\section{Competing interests}

The authors declare that they have no competing interests.

\section{Author details}

${ }^{1}$ College of Biological Science and Agriculture, Qiannan Normal University for Nationalities, Duyun 558000, Guizhou, China. ${ }^{2}$ Key Laboratory of System Bio-medicine of Jiangxi Province, Jiujiang University, Jiujiang 332000, Jiangxi, China. ${ }^{3}$ College of Basic Medical Science, Jiujiang University, Jiujiang 332000, Jiangxi, China.

Received: 23 April 2019 Accepted: 26 August 2019

Published online: 31 August 2019

References

1. Hackett G. Type 2 diabetes and testosterone therapy. World J Mens Health. 2019;37:31-44.

2. Bieniek JM, Kashanian JA, Deibert CM, Grober ED, Lo KC, Brannigan RE, et al. Influence of increasing body mass index on semen and reproductive hormonal parameters in a multi-institutional cohort of subfertile men. Fertil Steril. 2016;106:1070-5.

3. Craig JR, Jenkins TG, Carrell DT, Hotaling JM. Obesity, male infertility, and the sperm epigenome. Fertil Steril. 2017;107:848-59.

4. Andersson AM, Jorgensen N, Frydelund-Larsen L, Rajpert-De Meyts $E$, Skakkebaek NE. Impaired Leydig cell function in infertile men: a study of 357 idiopathic infertile men and 318 proven fertile controls. J Clin Endocrinol Metab. 2004:89:3161-7.

5. Stolba P, Kvapil M, Wichterle D, Dvorak P. Kinetics of free fatty acids in hypertriglyceridemia. Evidence for different types of insulin resistance. Ann N Y Acad Sci. 1993:683:373-4.

6. Manco M, Mingrone G, Greco AV, Capristo E, Gniuli D, De Gaetano A, et al. Insulin resistance directly correlates with increased saturated fatty acids in skeletal muscle triglycerides. Metabolism. 2000;49:220-4.

7. Warensjo E, Riserus U, Vessby B. Fatty acid composition of serum lipids predicts the development of the metabolic syndrome in men. Diabetologia. 2005:48:1999-2005.

8. Mu Y, Yan WJ, Yin TL, Zhang Y, Li J, Yang J. Diet-induced obesity impairs spermatogenesis: a potential role for autophagy. Sci Rep. 2017;7:43475.

9. Lu ZH, Mu YM, Wang BA, Li XL, Lu JM, Li JY, et al. Saturated free fatty acids, palmitic acid and stearic acid, induce apoptosis by stimulation of ceramide generation in rat testicular Leydig cell. Biochem Biophys Res Commun. 2003;303:1002-7. 
10. Cnop M, Foufelle F, Velloso LA. Endoplasmic reticulum stress, obesity and diabetes. Trends Mol Med. 2012;18:59-68.

11. Rashid HO, Yadav RK, Kim HR, Chae HJ. ER stress: autophagy induction, inhibition and selection. Autophagy. 2015;11:1956-77.

12. Guzel E, Arlier S, Guzeloglu-Kayisli O, Tabak MS, Ekiz T, Semerci N, et al. Endoplasmic reticulum stress and homeostasis in reproductive physiology and pathology. Int J Mol Sci. 2017;18.

13. Kim JH, Park SJ, Kim TS, Park HJ, Park J, Kim BK, et al. Testicular hyperthermia induces unfolded protein response signaling activation in spermatocyte. Biochem Biophys Res Commun. 2013;434:861-6.

14. Sovolyova N, Healy S, Samali A, Logue SE. Stressed to death - mechanisms of ER stress-induced cell death. Biol Chem. 2014;395:1-13.

15. Weisberg SP, Leibel R, Tortoriello DV. Dietary curcumin significantly improves obesity-associated inflammation and diabetes in mouse models of diabesity. Endocrinology. 2008;149:3549-58.

16. Mu Y, Yan WJ, Yin TL, Yang J. Curcumin ameliorates highfat dietinduced spermatogenesis dysfunction. Mol Med Rep. 2016;14:3588-94.

17. Maheshwari RK, Singh AK, Gaddipati J, Srimal RC. Multiple biological activities of curcumin: a short review. Life Sci. 2006;78:2081-7.

18. Shehzad A, Khan S, Sup LY. Curcumin molecular targets in obesity and obesity-related cancers. Future Oncol. 2012;8:179-90.

19. Savini I, Catani MV, Evangelista D, Gasperi V, Avigliano L. Obesity-associated oxidative stress: strategies finalized to improve redox state. Int J Mol Sci. 2013;14:10497-538.

20. Afrin R, Arumugam S, Soetikno V, Thandavarayan RA, Pitchaimani $V$, Karuppagounder $V$, et al. Curcumin ameliorates streptozotocin-induced liver damage through modulation of endoplasmic reticulum stress-mediated apoptosis in diabetic rats. Free Radic Res. 2015;49:279-89.

21. Rashid K, Chowdhury S, Ghosh S, Sil PC. Curcumin attenuates oxidative stress induced NFkappaB mediated inflammation and endoplasmic reticulum dependent apoptosis of splenocytes in diabetes. Biochem Pharmacol. 2017;143:140-55.

22. Guan G, Lei L, LV Q, Gong Y, Yang L. Curcumin attenuates palmitic acidinduced cell apoptosis by inhibiting endoplasmic reticulum stress in H9C2 cardiomyocytes. Hum Exp Toxicol. 2019;960327119836222.

23. Katib A. Mechanisms linking obesity to male infertility. Cent European J Urol. 2015;68:79-85.

24. Sallmen M, Sandler DP, Hoppin JA, Blair A, Baird DD. Reduced fertility among overweight and obese men. Epidemiology. 2006;17:520-3.

25. Park M, Sabetski A, Kwan Chan Y, Turdi S, Sweeney G. Palmitate induces ER stress and autophagy in $\mathrm{H} 9 \mathrm{c} 2$ cells: implications for apoptosis and adiponectin resistance. J Cell Physiol. 2015;230:630-9.

26. Sakamoto A, Saotome M, Hasan P, Satoh T, Ohtani H, Urushida T, et al. Eicosapentaenoic acid ameliorates palmitate-induced lipotoxicity via the AMP kinase/dynamin-related protein-1 signaling pathway in differentiated H9c2 myocytes. Exp Cell Res. 2017;351:109-20.

27. Zhang $Y$, Yang $X$, Shi H, Dong L, Bai J. Effect of alpha-linolenic acid on endoplasmic reticulum stress-mediated apoptosis of palmitic acid lipotoxicity in primary rat hepatocytes. Lipids Health Dis. 2011;10:122.

28. Yang L, Guan G, Lei L, Lv Q, Liu S, Zhan X, et al. Palmitic acid induces human osteoblast-like Saos-2 cell apoptosis via endoplasmic reticulum stress and autophagy. Cell Stress Chaperones. 2018;23:1283-94.

29. Pardo V, Gonzalez-Rodriguez A, Muntane J, Kozma SC, Valverde AM. Role of hepatocyte S6K1 in palmitic acid-induced endoplasmic reticulum stress, lipotoxicity, insulin resistance and in oleic acid-induced protection. Food Chem Toxicol. 2015;80:298-309.

30. Katsoulieris E, Mabley JG, Samai M, Green IC, Chatterjee PK. Alpha-linolenic acid protects renal cells against palmitic acid lipotoxicity via inhibition of endoplasmic reticulum stress. Eur J Pharmacol. 2009:623:107-12.

31. Afrin MR, Arumugam S, Rahman MA, Karuppagounder $V$, Harima M, Suzuki $\mathrm{H}$, et al. Curcumin reduces the risk of chronic kidney damage in mice with nonalcoholic steatohepatitis by modulating endoplasmic reticulum stress and MAPK signaling. Int Immunopharmacol. 2017:49:161-7.

32. Zhu H, Fan $Y$, Sun $H$, Chen L, Man X. Curcumin inhibits endoplasmic reticulum stress induced by cerebral ischemia-reperfusion injury in rats. Exp Ther Med. 2017;14:4047-52.

33. Wan S, Sun Y, Qi X, Tan F. Improved bioavailability of poorly water-soluble drug curcumin in cellulose acetate solid dispersion. AAPS PharmSciTech. 2012;13:159-66
34. Hu L, Shi Y, Li JH, Gao N, Ji J, Niu F, et al. Enhancement of Oral bioavailability of curcumin by a novel solid dispersion system. AAPS PharmSciTech. 2015;16:1327-34.

35. Song IS, Cha JS, Choi MK. Characterization, in vivo and in vitro evaluation of solid dispersion of curcumin containing d-alpha-Tocopheryl polyethylene glycol 1000 succinate and mannitol. Molecules. 2016;21.

36. Gao Y, Chen G, Luan X, Zou M, Piao H, Cheng G. Improved Oral absorption of poorly soluble curcumin via the concomitant use of Borneol. AAPS PharmSciTech. 2019;20:150.

37. Onoue S, Takahashi H, Kawabata Y, Seto Y, Hatanaka J, Timmermann B, et al Formulation design and photochemical studies on nanocrystal solid dispersion of curcumin with improved oral bioavailability. J Pharm Sci. 2010;99:1871-81.

38. Hou Y, Wang $H$, Zhang F, Sun F, Xin M, Li M, et al. Novel selfnanomicellizing solid dispersion based on rebaudioside a: a potential nanoplatform for oral delivery of curcumin. Int J Nanomedicine. 2019;14:557-71.

39. Zhang Q, Suntsova L, Chistyachenko YS, Evseenko V, Khvostov MV, Polyakov $N E$, et al. Preparation, physicochemical and pharmacological study of curcumin solid dispersion with an arabinogalactan complexation agent. Int J Biol Macromol. 2019;128:158-66.

40. Feng R, Luo C, Li C, Du S, Okekunle AP, Li Y, et al. Free fatty acids profile among lean, overweight and obese non-alcoholic fatty liver disease patients: a case - control study. Lipids Health Dis. 2017;16:165.

41. Niu Z, Lin N, Gu R, Sun Y, Feng Y. Associations between insulin resistance, free fatty acids, and oocyte quality in polycystic ovary syndrome during in vitro fertilization. J Clin Endocrinol Metab. 2014;99:E2269-76.

42. Clore JN, Allred J, White D, Li J, Stillman J. The role of plasma fatty acid composition in endogenous glucose production in patients with type 2 diabetes mellitus. Metabolism. 2002;51:1471-7.

43. Yao Q, Ke ZQ, Guo S, Yang XS, Zhang FX, Liu XF, et al. Curcumin protects against diabetic cardiomyopathy by promoting autophagy and alleviating apoptosis. J Mol Cell Cardiol. 2018;124:26-34.

44. Luo DY, Yang G, Liu JJ, Yang YR, Dong Q. Effects of varicocele on testosterone, apoptosis and expression of StAR mRNA in rat Leydig cells. Asian J Androl. 2011;13:287-91.

\section{Publisher's Note}

Springer Nature remains neutral with regard to jurisdictional claims in published maps and institutional affiliations.
Ready to submit your research? Choose BMC and benefit from:

- fast, convenient online submission

- thorough peer review by experienced researchers in your field

- rapid publication on acceptance

- support for research data, including large and complex data types

- gold Open Access which fosters wider collaboration and increased citations

- maximum visibility for your research: over $100 \mathrm{M}$ website views per year

At $\mathrm{BMC}$, research is always in progress.

Learn more biomedcentral.com/submissions 